politik fanden, sondern mehr mechanistisch anmutende Vorstellungen, die einem naiven politischen Gestaltungsoptimismus und dem Irrglauben an ein "fine tuning“" der wirtschaftlichen Entwicklung Vorschub leisteten. Dies machte es leicht, keynesianische Politik mit einem Entzünden wirkungsloser Strohfeuer und einem Marsch in die Staatsverschuldung gleichzusetzen.

Herzliche Grïße,

Ihr Bert Rürup

\title{
Der Mahner
}

Lieber John Maynard Keynes,

zu Ihrem 125. Geburtstag wünsche ich Ihren Theorien, dass sie nicht mehr so häufig politisch missbraucht werden. In Deutschland beruft man sich auf Sie, wenn man höhere Löhne fordert, weil die angeblich mehr Kaufkraft und Nachfrage schaffen. Einen solchen Unsinn haben Sie natürlich nie behauptet. Ich wünschte mir und Ihnen außerdem, dass die Möchtegern-Ökonomen, die sich auf Sie berufen, endlich die so meisterlich von Ihnen ausgearbeitete Rolle der Liquiditätspräferenz begreifen würden. Dann wüssten diese Leute, dass Nachfrage in einem Land immer nur dann und dem Maße verloren gehen kann, wie die Geldhorte steigen, und dass eine Volkswirtschaft mit normalen Zinsen niemals unter einem Nachfragedefizit leiden kann, wenn die Notenbank eine ausreichende Geldversorgung sicherstellt. Ich finde es immer wieder erschreckend, wie wenig diejenigen, die Sie für alles und jedes vereinnahmen, von der Geld- und Kreislauftheorie verstanden haben, die Sie uns hinterlassen haben. Ruhen Sie aber dennoch in Frieden. Wir Ökonomen werden den Kampf gegen den Missbrauch Ihres Namens weiterhin kämpfen. Sie haben sich um das Große gekümmert, und wir kümmern uns um die Details.

Mit herzlichem Gruß,

Ihr Hans-Werner Sinn 